\section{Review}

Dorothy Crowfoot

Hodgkin Laboratories, University Division of

Medicine, Bristol

Royal Infirmary,

Bristol BS2 8HW, UK

$\mathrm{R}$ Wiggins

A P Corfield

Centre for Biomedical Sciences, School of Applied Sciences, University of Wales Institute Cardiff Western Ave, Cardiff CF5 2YB, UK

S J Hicks

University

Department of

Obstetrics and

Gynaecology,

St Michael's Hospital,

Southwell Street,

Bristol BS2 8EG, UK

P W Soothill

Department of Microbiology, Bart's and the London NHS Trust, Smithfield, London EC1A 7BE, UK

M R Millar

Correspondence to: Dr A P Corfield tony.corfield@bristol.ac.uk

Accepted for publication 30 August 2001

\title{
Mucinases and sialidases: their role in the pathogenesis of sexually transmitted infections in the female genital tract
}

\author{
R Wiggins, S J Hicks, P W Soothill, M R Millar, A P Corfield
}

\begin{abstract}
Background: Mucinases and sialidases contribute to the process of invasion and colonisation in many conditions and infections of the female reproductive tract by degrading the protective cervical mucus. The role of hydrolytic enzymes in the pathogenesis of sexually transmitted diseases and their effect on cervical mucus are discussed in this review.

Methods: Articles were searched for using the keywords "sialidase," "mucinase," "protease," and "sexually transmitted infections." As well as review and other articles held by our group, searches were conducted using PubMed, Grateful Med, and the University of Bath search engine, BIDS. Results: Numerous publications were found describing the production of hydrolytic enzymes in sexually transmitted diseases. Because the number of publications exceeded the restrictions imposed on the size of the review, the authors selected and discussed those which they considered of the most relevance to sexually transmitted infections.
\end{abstract}

(Sex Transm Inf 2001;77:402-408)

Keywords: mucinase; sialidase; microbial protease

\section{Introduction}

Micro-organisms depend on successful colonisation of the host in order to reproduce and multiply. A major impediment to this process is the mucosal barrier, which exists in a secreted or membrane bound form. In order to breach this barrier, micro-organisms may produce a range of hydrolysing enzymes called mucinases. Mucinases are enzymes capable of degrading mucins (the complex high molecular weight molecules that are the major nonaqueous components of mucous gels). Mucins are glycoproteins; therefore, they may be targets for many diverse proteolytic and glycolytic enzymes. Partial or complete degradation of mucin molecules by microbial enzymes is often a fundamental step in disruption of defensive mucosal barriers, as these constitute direct interfaces between internal and external environments. The possible contribution of mucin degrading enzymes to the pathogenesis of infection is, therefore, not to be underestimated. Recent evidence suggests that mucinases in particular may play a vital part in the aetiology of certain conditions and/or infections of the female genital tract, and may also be involved in adverse sequelae resulting from microbial colonisation. ${ }^{12}$ This review approaches the role of mucin degrading enzymes from the potential interaction of microorganisms with the cervical mucus barrier, and discusses the contribution that mucin degrading enzymes may make to microbial colonisation of the reproductive tract.

Protective properties of cervical mucus Mucus comprises water, glycoproteins (mucins), and ions. Mucous gels exhibit nonspecific antibacterial capabilities as they contain molecules such as lactoferrin, lysozyme, and immunoglobulins. ${ }^{3}$ In the female reproductive tract a primary function of the cervical mucus is the defence of the upper reproductive tract from microbial invasion. Mucus has an integrated antibacterial function. ${ }^{4}$ The proteins that occur in the mucus, including lactoferrin, lysozyme, and secretory $\operatorname{IgA}$, are part of this defence system. Their purpose is to be antibacterial although they are non-specific in activity.

Of potentially greater importance for the protection of the upper genital tract are the cervical mucins. These molecules dictate the rheological properties which determine the amount and viscosity of the mucosal flow. Physical clearance of microbes by mucosal secretions is a most effective first line defence: millions of micro-organisms a day are cleared from the body cavities by this method alone. ${ }^{5}$ Cyclical differences in mucus viscosity may also allow greater foreign infiltration at the times when the cervical mucus is less viscous. ${ }^{6}$ Terminal glycosylation of cervical mucins may be the origin of mucus rheology, although firm evidence of the importance of the terminal sugars during the menstrual cycle and pregnancy remains elusive.

\section{Cervical mucins: structural and \\ functional characteristics}

Mucins are major components of mucous gels. They are large glycoproteins with molecular weights in the range of $5 \times 10^{5}-4 \times 10^{6} \mathrm{Da}^{3}$ They are highly glycosylated (up to $85 \%$ of their dry weight may be carbohydrate): this is thought to afford them protection from proteolysis. ${ }^{7} \mathrm{Un}$ like the majority of glycoproteins, mucins are predominantly O-glycosylated (fig 1).

The carbohydrate component of a mucin molecule is particularly important in the context of mucinases, as the majority of degradative enzymes studied affect carbohydrate 


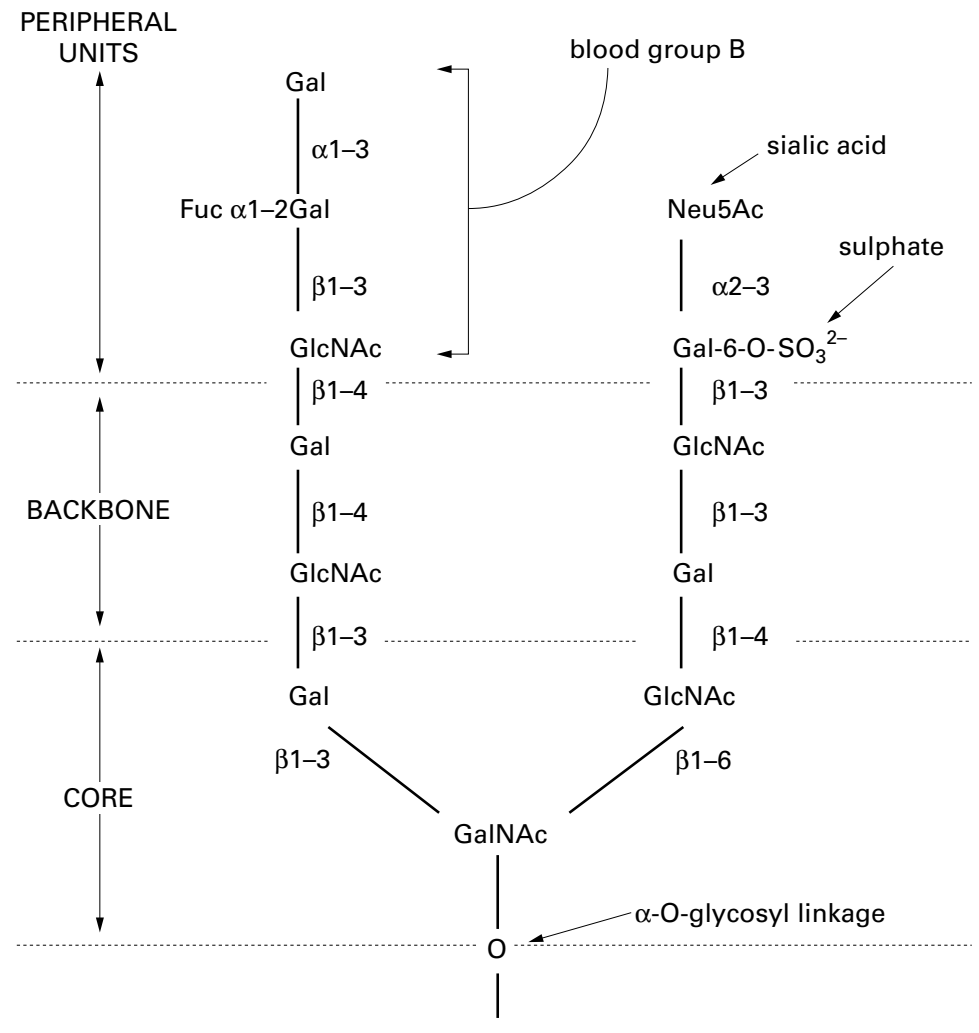

POLYPEPTIDE >>>Ser/Thr >>>

Figure 1 O-glycosylation of mucin. Theoretical oligosaccharide structure showing the core, backbone, and peripheral domains. The O-glycosidic linkage to the polypeptide serine (Ser) and threonine (Thr) residues is through $N$-acetylgalactosamine (GalNAc). Backbone repeats of galactose ( $\mathrm{Gal}$ ) and $\mathrm{N}$-acetylglucosamine (GlcNAc) are shown. Sialic acid (Neu5Ac), sulphate ( $\left.\mathrm{SO}_{3}{ }^{2-}\right)$ and fucose (Fuc) reside at peripheral termini.

side chains. The traditional view is that carbohydrate side chains protect the central protein core from attack by proteolytic enzymes. ${ }^{7}$ The carbohydrate chains of cervical mucins are usually 9-10 monosaccharide units in length, composed of the residues L-fucose, $\mathrm{N}$-acetylneuraminic acid (sialic acid), galactose, $\mathrm{N}$-acetyl-galactosamine, and N-acetylglucosamine. $^{8}$ Of these, an $\mathrm{N}$-acetylgalactosamine is always at the reducing end of the chain and O-linked to serine or threonine (fig 1). Sulphate residues occur at $\mathrm{N}$-acetylglucosamine or galactose. The sugars at the non-reducing termini are usually $\alpha$-linked fucose or sialic acid, the amounts of which are inversely proportional. ${ }^{8}$ The internal sugars are $\beta$-linked except for the $\mathrm{N}$-acetylgalactosamine, which is attached to the protein core. The cyclic variation in L-fucose and sialic acid is reflected in the level of activity of the glycosyltransferases responsible for the addition of these sugars. Higher sialyltransferase activity has been identified during the proliferative and luteal phases. Fucosyltransferase activity appears highest in the proliferative phase, reduces slightly during the ovulatory phase, and is very low during the luteal phase. ${ }^{8}$ This indicates cyclic changes in the oligosaccharide composition of cervical mucins, which may have different effects on the functions of the mucus as a whole.

One of the mechanisms that permits mucin molecules to form viscoelastic structures is the stiff, bristling arrangement of the carbohydrate side chains along the peptide backbone. Ionic interactions between the carbohydrate and the core peptide induce a stiff and extended conformation. Negatively charged terminal carboxyl groups on sialic acid residues and sulphate groups that occur on $\mathrm{N}$-acetylglucosamine and galactose confer rigidity to the mucin molecules. ${ }^{79}$ This mutual repulsion occurs both between the sugar molecules on the same chain and between neighbouring molecules. ${ }^{7}$ Crosslinking of cervical mucins increases during the luteal phase of the menstrual cycle, forming a meshed structure that is rigid, plug-like, and less penetrable to sperm. During the proliferative phase, when sperm penetration is beneficial, the mucins are less rigidly packed and the mucus itself has a thinner, more watery appearance. ${ }^{8}$

The terminal glycosylation of mucins may be the main determining factor of the rheological properties of mucus. If the mutual repulsive charge both between the mucin molecules and between the carbohydrate side chains of individual mucins is lost, the arrangement of mucin molecules in solution is altered, and viscosity of the mucus gel decreases. Alterations in cervical mucus viscosity during the menstrual cycle may allow greater penetration of mucus by invading pathogens at certain times in the cycle. $^{10}$

\section{Mucin genes in the cervix}

Investigations of the expression of mucin genes in the human cervix have identified a total of six of the family of nine MUC genes expressed by the endocervical epithelium. MUC2, MUC5B, MUC5AC, and MUC6 all occur on chromosome $11 \mathrm{p} 15.5$, and are regarded as the major gel forming species. ${ }^{11}{ }^{12}$ Sequence data have identified MUC5B as the dominant gel forming mucin gene, although MUC5AC and MUC6 are also expressed. ${ }^{11}$ MUC5B has been identified in the epithelium lining the cervical canal, as well as in the glands, ${ }^{11}{ }^{12}$ suggesting a further functional role for this mucin in the cervix. Both MUC1 and MUC4 are membrane associated mucins expressed by the stratified epithelia of the ectocervix and vagina. ${ }^{13}$

Determination of the expression of mucin genes in the cervix has clarified investigations into the cyclical alterations of mucus rheology. Audie et $a l^{13}$ proposed that synthesis of the apomucin may be controlled by hormonal secretion. They found the transcription of MUC4 to be increased during the luteal phase. In contrast, Gipson et $a l^{12}$ found an inverse relation between levels of MUC5B and MUC4 mRNA and progesterone, with no apparent correlation with oestradiol. Posttranscriptional levels of MUC5B were raised in the mid-cycle, compared to early and late stage cycle, indicating a role for this mucin in sperm transport. ${ }^{14}$

\section{Mucin degrading enzymes (mucinases)}

Enzymes that are capable of degrading mucins have been widely studied for several decades, although their prominence in the literature has been somewhat superseded by studies carried out specifically on sialidases. Enzymes other 
than sialidase that may play a role in mucin breakdown include other glycosidases, proteases, and sulphatases. Mucin degrading enzymes are being targeted in the literature, particularly with regard to their role as virulence agents, and their possible effects on immune function. ${ }^{15}$ The treatment of infections using enzyme inhibitors has been an obvious direction for research; inhibitors of influenza $\mathrm{A}$ and $\mathrm{B}$ sialidases have recently been developed. ${ }^{16}$ However, the sheer diversity of enzymes of therapeutic interest means that such investigations require substantial investment.

\section{Enzymes that may exert degradative effects against mucus}

Many bacteria are known to produce proteases or glycosidases that degrade host defence components of mucus, such as $\operatorname{sIgA}^{17}$ or lactoferrin. ${ }^{18}$ These enzymes may exert effects on the physical barrier presented by mucus or may enhance bacterial adhesion and hence colonisation. Detailed studies of the specificities and effects of many such enzymes have yet to be undertaken

GLYCOSIDASES

$\beta$-D-galactosidase, $\quad \mathrm{N}$-acetyl- $\beta$-D-galactosaminidase, $\alpha$-fucosidases, sialidase (see sialidases below), and N-acetyl- $\beta$-D-glucosaminidase cleave sugars from mucin oligosaccharides. $^{2}$ These enzymes may act in conjunction with each other to promote complete degradation of the glycoprotein..$^{219}{ }^{20}$ For example, the protozoan Trichomonas vaginalis generates a range of glycosidases that are capable of complete degradation of mucin. ${ }^{21}$

PROTEASES

Proteases are likely to exhibit two modes of action in mucin degradation: (1) initial cleavage at non-glycosylated regions, leading to reduced viscoelasticity and disruption of gel structure; and (2) final disruption of exposed protein core after deglycosylation by other enzymes..$^{20}$ If this is the case, it would be logical for bacterial species, particularly those that are symbiotic, to produce proteases, as well as a number of other mucin degrading enzymes. ${ }^{22-25}$

\section{SULPHATASES}

Several organisms are known to produce sulphatases which act upon respiratory and gastrointestinal mucins. ${ }^{26}$ The loss of terminal sulphate residues may be an important rate limiting factor in mucin degradation, ${ }^{26}$ as this may expose underlying sugars to further enzymatic attack. The sulphate released by sulphatase action may also be utilised for fuel by other organisms. ${ }^{27}$ However, the specific function of sulphate in cervical mucus is still an unknown quantity; its significance in conferring rigidity and protection to the mucus gel has not been established. ${ }^{28}$

SIALIDASES (NEURAMINIDASES): FUNCTIONAL CHARACTERISTICS, REQUIREMENTS, AND MECHANISMS OF ACTION

Sialidases have been subject to much investigation since their discovery in the $1940 \mathrm{~s},{ }^{9}$ and



Figure 2 Sialic acid (N-acetyl-D-neuraminic acid, Neu5Ac).

their occurrence in bacteria and viruses is widespread. Notable studies, concerned with the detection and purification of microbial sialidases include those of Drzeniek ${ }^{29}$ and Corfield et al. $^{30}$

Sialidases cleave terminal sialic acids from glycoproteins and glycolipids, unmasking other sugars on their carbohydrate side chains. After the released sialic acid has been degraded by acylneuraminate pyruvate lyase to yield $\mathrm{N}$-acetylmannosamine, the resulting carbon skeleton can be utilised as an energy source by some bacteria. ${ }^{91}$ Sialidases tend to be highly substrate specific. They may target particular types of complex molecules, such as glycoproteins or glycolipids; specific sugar linkages $(\alpha 2-3,2-6$, or $2-8)$; or may be sensitive to the nature of the linkage sugar itself (D-galactose, $\mathrm{N}$-acetyl-D-galactosamine, etc). Sialidases are most commonly secreted, but may be cell bound. $^{9}$

Sialidase substrates - sialic (neuraminic) acids Sialic acids are acidic nine carbon sugars, which frequently occupy the non-reducing termini of complex glycoconjugates. There are a large number of sialic acid derivatives found throughout living systems. ${ }^{32} 33$ The most prominent member of the sialic acid family is $\mathrm{N}$-acetylneuraminic acid (Neu5Ac) (fig 2). The wide variety of sialic acids appears to dictate their distinct and important biological roles. Their terminal and, therefore relatively exposed, positions render them vulnerable to degradation, and protection against the action of sialidases can be afforded by substitution of $\mathrm{O}$-acetyl esters. ${ }^{93} \mathrm{O}$-acetylation confers resistance to enzymatic attack, resulting in a decrease in or total inhibition of sialidase activity. The extent of O-acetylation with regard to reproductive tract mucins requires investigation, and may be of critical importance in assessing the possible degradation of cervical mucus.

Sialic acid and sialidases in cell adhesion and cell recognition

Adherence to epithelial cells is exhibited both by invading pathogens and by non-pathogenic micro-organisms. ${ }^{34}$ Although bacterial adhesins act as receptors for carbohydrate epitopes present on various components of mucus, and can therefore aid the entrapment of bacteria 
Table 1 Enzymes produced by microbial organisms in the genital tract

\begin{tabular}{|c|c|c|c|c|}
\hline Organisms & Glycosidase (other than sialidase) & Sialidase & Proteinase & References \\
\hline Candida albicans & $\mathrm{N}$-acetylglucosaminidase & Probably not & Aspartyl proteinase & 24,63 \\
\hline$N$ gonorrhoeae & no & no & IgA1 proteinase & \\
\hline$T$ vaginalis & $\begin{array}{l}\mathrm{N} \text {-acetylglucosaminidase } \\
\mathrm{N} \text {-acetylgalactosaminidase }\end{array}$ & yes & Cysteine proteinases & $21,58,59,61$ \\
\hline Group B streptococcus & Hyaluronidase & no & $\begin{array}{l}\text { Extracellular proteases. } \\
\text { C5A cell associated peptidase }\end{array}$ & 65 \\
\hline Chlamydia trachomatis & no? & ? & ? & 1,66 \\
\hline Gardnerella vaginalis & no & yes & IgA protease? & $36,38,57$ \\
\hline Prevotella spp & Sulphatase & yes & IgA protease & $26,35,38,48$ \\
\hline Bacteroides fragilis & $\begin{array}{l}\alpha \text {-Fucosidase } \\
\beta \text {-galactosidase } \\
\mathrm{N} \text {-acetyl- } \alpha \text {-galactosidase } \\
\mathrm{N} \text {-acetyl- } \beta \text {-glucosaminidase }\end{array}$ & yes & Extracellular proteases & $22,45,46,47$ \\
\hline Mycoplasma hominis & $\begin{array}{l}\alpha \text { and } \beta \text {-glucosidase } \\
\beta \text {-galactosidase } \\
\beta \text {-N-acetylglucosaminidase }\end{array}$ & yes & No? & $1,51,50$ \\
\hline Ureaplasma urealyticum & no & no & IgA protease & 51 \\
\hline Fusobacterium nucleatum & no & no & No & 48,54 \\
\hline Mobiluncus spp & $\beta$-Galactosidase & yes? & No? & $1,35,53$ \\
\hline Peptostreptococcus spp & yes? & no & No & 37,56 \\
\hline
\end{tabular}

within mucus, they may also facilitate bacterial attachment to underlying epithelial cells, and therefore be detrimental to the host. Adhesion sites can be presented by the oligosaccharide side chains of mucin. ${ }^{30}$ Unmasking of internal sugars by removal of terminal sugars may increase binding opportunities for microorganisms. ${ }^{50}$ Removal of sialic acid, with the corresponding loss of negative charge, may both permit bacterial adhesion and expose other sugar residues to hydrolysis. In contrast, increased sialylation of mucins may inhibit bacterial binding. ${ }^{5}$ The negative repulsive charge conferred by sialic acids and sulphate residues may also play a part in preventing adhesion of pathogens. ${ }^{35}$

POSSIBLE CONTRIBUTIONS OF MUCIN DEGRADING ENZYMES OR ADHESION SYSTEMS TO REPRODUCTIVE TRACT INFECTIONS

Microbial mucin degrading enzymes are either significantly associated with certain genital tract conditions and sexually transmitted infections or are known to be produced by the offending micro-organisms (table 1). Of these, the most widely investigated have been bacterial vaginosis $(\mathrm{BV})^{12^{36-39}}$ and $T$ vaginalis. ${ }^{122}$ The extent and nature of their degradative activity against human reproductive tract mucins has not, however, been investigated in detail. Substrate specificity and enzyme inducibility in the presence of human cervical mucins have not been determined, nor is there yet any evidence of direct toxic effects from enzymes of pathogenic origin against host tissues. $^{9}$

It is likely that, particularly between BV organisms, but probably also between other micro-organisms in the female genital tract, a degree of mutually beneficial cohabitation exists on the mucosal surfaces in the form of a biofilm. ${ }^{40}$ Bacteria which utilise glycogen as an energy source, such as commensal Lactobacillus spp may contribute to normal mucin turnover by the production of mucin degrading enzymes such as sialidase (Wiggins et al, unpublished observations). The activity of the mucin degrading enzyme(s) produced by certain strains of lactobacilli may be less than that produced by BV related bacteria such as Prevotella disiens and bivia, and therefore may be sufficient to contribute to normal mucin regulation. Organisms with potentially pathological enzyme activity, such as BV related bacteria, are maintained in small numbers unless an unspecified event occurs which changes the flora from lactobacilli to a dominance of BV organisms. Since BV is defined as a condition in which various species of anaerobes, Gardnerella vaginalis, and often Mycoplasmas coexist, it is likely that there is some form of co-dependency between these organisms. This may involve the production of mutually beneficial mucin degrading enzymes - for example, the production of sialidases that recognise specific sugar linkages by certain bacteria, and the production of other glycosidases (and possibly also proteases) by different species. The action of such enzymes could both generate attachment sites on the mucosal surfaces and produce a source of nutrition for the bacteria from mucin breakdown. However, although progress has been made in identifying enzymes produced by genital tract infections/conditions, the likelihood of cooperation between the organisms is at present speculative. Below follows a description of the principal enzyme producing organisms that colonise the female genital tract. Table 1 includes other organisms that can produce genital tract infection, and indicates the enzymes produced by these organisms that have so far been identified.

\section{Bacterial vaginosis related bacteria}

Bacterial vaginosis occurs when the commensal lactobacilli in the vagina are overwhelmed by bacteria that normally inhabit the vagina in small numbers. ${ }^{2}$ It is unclear why this change in colonisation occurs. Lactobacilli maintain an acidic vaginal $\mathrm{pH}$ whereas $\mathrm{BV}$ related bacteria thrive in more alkaline conditions; therefore the reduction of lactobacilli can create an environment favourable to the growth of BV bacteria. The mechanisms causing this loss of lactobacilli are, however, not known at this stage. It seems likely that the BV related bacteria may act in synergy to maximise colonisation opportunities; the production of mucin degrading enzymes by many of these bacteria may be a step in promoting adhesion to the underlying 
epithelium. Recent work has shown that cervical mucins from women with high glycosidase activity demonstrate differences in electrophoretic mobility compared to cervical mucins from women with low or absent glycosidase activity (Wiggins et al, unpublished). This may be due to degradation of cervical mucins by enzymes produced by BV bacteria, which would allow colonisation of the upper reproductive tract, and help explain the occurrence of chorioamnionitis in the pregnant population.

\section{Bacteroides spp; Bacteroides fragilis}

Bacteroides spp present in the reproductive tract have been associated with sialidase activity against several substrates. ${ }^{34-36}$ Bacteroides fragilis is a normal inhabitant of the human colon which is sometimes associated with $\mathrm{BV}{ }^{36}$ Sialidase deficient mutant strains of $B$ fragilis fare less well than wild type strains when grown in tissue culture monolayers, suggesting that sialidase may have a role in normal bacterial function. ${ }^{41}$ Several $B$ fragilis strains possess an adhesin which mediates attachment to mammalian epithelial cells via a Gal containing cell surface receptor that is exposed by sialidase treatment. ${ }^{42} \mathrm{~A}$ different study found only a very slight increase in $B$ fragilis haemagglutination of colonic epithelial cells with sialidase treatment, which suggests that sialidase may not be required for adherence in all instances. ${ }^{43}$ Haemagglutination and binding of $B$ fragilis to bovine submaxillary mucin (BSM) is inhibited by sialic acid, suggesting that $B$ fragilis may also use sialic acid as a binding ligand in certain situations. ${ }^{44}$

Sialidase production by $B$ fragilis has been reported, ${ }^{22}$ and the enzyme isolated by Berg et $a l^{45}$ showed degradation of BSM and porcine gastric mucin. One strain of $B$ fragilis exhibits a stronger preference for sialyl $\alpha$ 2-8 linkages than for $2-3$ or $2-6 .{ }^{46} B$ fragilis exhibits sulphatase activity against colonic mucin, ${ }^{26}$ but action against cervical mucin has not been examined.

One strain of $B$ fragilis produces enzymes directed against $\alpha$-Fuc, $\beta$-Gal, $\alpha$-GalNAc, and $\beta-$ GlcNAc when grown with porcine gastric mucin as a substrate. ${ }^{25} B$ fragilis is also reported to express extracellular proteases. ${ }^{47}$ This wide range of activities suggests that $B$ fragilis may be capable of extensive mucin degradation.

\section{Prevotella bivia and Prevotella disiens}

Prevotella spp are capable of degrading $\operatorname{IgA}^{17}$ and have been linked with glycosidase activity in the oral cavity. ${ }^{48} \mathrm{~A}$ mucin sulphatase is produced by Prevotella spp isolated from the colon $^{26}$ and cervical mucus is highly sulphated. ${ }^{28} 49$ Therefore, the production of a sulphatase might also be expected at this anatomical site.

$P$ bivia and $P$ disiens in the reproductive tract have been associated with sialidase activity against glycoprotein substrates. ${ }^{36} 37$ However, experiments confirming this sialidase activity using reproductive tract mucins as substrates remain to be undertaken.

\section{Mycoplasmas}

Mycoplasma hominis exhibits $\alpha$ and $\beta$-glucosidase, $\beta$-galactosidase, and $\beta-\mathrm{N}$ acetylglucosaminidase activities. ${ }^{50} \mathrm{McGregor}$ et $a l^{1}$ noted that mucinase activity against BSM was present in the vaginal washes of women colonised with $M$ hominis in the absence of BV. Sialidase activity against the substrate 2-(3methoxyphenyl)-N-acetyl-D-neuraminic acid has been reported in isolates from BV cases. ${ }^{1}$

In the female reproductive tract, $M$ hominis does not show any ability to degrade $\operatorname{IgA} .^{51}$ Another mycoplasma, Ureaplasma urealyticum, is known to be capable of degrading $\operatorname{IgA}$, although no glycosidase or mucinase activity has been identified. ${ }^{51}$ Adherence of $U$ urealyticum to epithelial cells can be blocked by the addition of sialic acid, suggesting that this organism recognises sialic acid containing receptors. ${ }^{52}$ Sialic acid containing mucins present in the female reproductive tract might therefore be expected to play a part in preventing adherence of $U$ urealyticum to the underlying epithelium, although this has not yet been investigated.

\section{Mobiluncus spp}

Mobiluncus mulieri and $M$ curtseii cultured from the female reproductive tract show no sialidase activity when tested against a 2-[4methylumbelliferyl]- $\alpha-\mathrm{D}-\mathrm{N}$-acetylneuraminic acid substrate. ${ }^{36}{ }^{37}$ However, McGregor et al $l^{1}$ using BSM and 2-(3-methoxyphenyl)-Nacetyl-D-neuraminic acid as substrates, reports both sialidase and mucinase activity in the vaginal fluid of women with BV; this activity is associated with the presence of Mobiluncus spp. $\beta$-Galactosidase activity has also been reported in Mobiluncus spp isolated from vaginal secretions. ${ }^{53}$ These results suggest that these organisms may be able to utilise mucin as a substrate.

\section{Fusobacterium nucleatum}

Fusobacteria are BV related organisms. Few studies however, have investigated their production of mucin degrading enzymes. Studies of oral strains of fusobacteria have proved negative for sialidase. ${ }^{48}$ In the oral cavity, Fusobacterium nucleatum adhesins bind to galactose containing receptors which may be exposed after treatment with endogenous sialidase. ${ }^{54}$ The binding of $F$ nucleatum to human erythrocytes and peripheral blood polymorphonuclear neutrophils is inhibited by GalNAc..$^{55}$ The ability of mucins containing Gal and GalNAc to block the adherence of $F$ nucleatum to epithelial cells in the female reproductive tract requires investigation; this may be of relevance when the potential oro-genital transmission of this organism is considered.

\section{Peptostreptococcus spp}

The enzyme activity of Peptostreptococcus spp against mucosal defence barriers has been tested by various researchers. $P$ micros did not degrade human lactoferrin in one published study. ${ }^{18}$ No sialidase activity was identified in Peptostreptococcus spp against 2-[4-methylumbelliferyl]- $\alpha$-D-N-acetylneuraminic acid. ${ }^{37}$ Peptostreptococcus spp have been linked to 
glycosidase activity in the gut; however, ${ }^{56}$ little further information on the degradative ability of these organisms is available.

\section{Gardnerella vaginalis}

Sialidase activity has been recognized in $G$ vaginalis isolates in a number of studies. ${ }^{13657}$ Degradative activity against BSM was associated with $G$ vaginalis in both the presence and absence of other BV related organisms. ${ }^{1}$

In one study, only $20 \%$ of BV related $G$ vaginalis isolates demonstrated sialidase activity, ${ }^{36}$ although activity was only tested against one synthetic substrate (2-[4-methylumbelliferyl]- $\alpha-\mathrm{D}-\mathrm{N}$-acetylneuraminic acid). The source of the enzyme (secreted or cell bound) was not identified in this study. However, a cell bound sialidase has been recognised in $G$ vaginalis. ${ }^{57}$ Its $\mathrm{pH}$ optimum of 5.5 would be appropriate at the raised vaginal $\mathrm{pH}$ seen in BV. In addition, high levels of sialidase activity in vaginal washings have been shown to correlate with IgA degradation. ${ }^{38}$

\section{Trichomonas vaginalis}

$T$ vaginalis produces enzymes which can degrade secretory IgA. Multiple proteinases have been detected, with different $\mathrm{pH}$ optima and sensitivity to inhibitors. ${ }^{58}$ These are mainly cysteine proteinases with MW of $30-60 \mathrm{kDa} .^{59}$ Cysteine proteinases are most frequently cited as potential virulence agents in the genital tract, although other proteinases of higher MW which are resistant to cysteine proteinase inhibitors have also been reported. ${ }^{60}$

Effective colonisation of epithelial cells in the genital tract by $T$ vaginalis is also the result of proteolytic degradation of the mucin. Lehker and Sweeney ${ }^{23}$ conducted an investigation into the adherence of $T$ vaginalis to mucin. Five proteinases tested from trichomonad isolate 24402 all degraded BSM, and the existence of a $T$ vaginalis lectin-like adhesin for binding to mucin was proposed. Connaris and Greenwell ${ }^{21}$ found that trichomonads were the only mucin dwelling protozoans to produce a full range of glycosidases capable of degrading mucin.

$T$ vaginalis also expresses a sialidase with shows specificity for $\alpha 2-3$ linked sialic acids, but which is unable to liberate $\alpha 2-6$ linked sialic acid from mucin. ${ }^{61}$ The enzyme is membrane bound and its possible significance in the genital tract is not established.

\section{Future directions}

The production of mucin degrading enzymes by pathogens is extremely important in the invasion and colonisation of host tissues. Glycoprotein binding/degrading interactions of micro-organisms may involve both secreted and membrane bound mucins and mucin-like molecules. Examination of the relation between pathogens and the glycoproteins involved in host defence should be undertaken, particularly in relation to current improvements in our knowledge of the genetic basis of host-pathogen interactions.
An obvious progression from such examinations would be the further development of specific and effective inhibitors of pathogenic enzymes. However, detailed investigations of the complex interactions between the microflora of the genital tract, particularly the female genital tract, are required. Therapeutic options should not threaten to disturb the delicate balance of a microenvironment that has evolved to the mutual advantage of the host and its normal microflora.

"Glycosidases such as neuraminidases and galactosidases can be used as markers for microbial infection, provided that the enzymatic activity can be . . identified as being of bacterial origin. The direct measurement of microbial enzymes offers great potential for the rapid diagnosis of infectious diseases." 62

\section{Abbreviations}

BSM (bovine submaxillary mucin), BV (bacterial vaginosis); Fuc (fucose); Gal (galactose); GalNAc (N-acetylgalactosamine); Glc (glucose); GlcNAc (N-acetylglucosamine); Man (mannose); PMN (polymorphonuclear neutrophils), human immunodeficiency virus 1 (HIV-1); sIgA (secretory immunoglobulin A).

This work was supported by grants from Tommy's Campaign, London, UK (grants 30 and 49).

Contributors: After a request to compile a review was received from the editor of $S T I$ by APC all authors discussed the scope of the work with respect to the outlines of the journal; RW and SJH took on the task of compiling the literature and writing the text, which was subsequently corrected and edited by APC and MRM; PWS then overviewed the paper.

1 McGregor JA, French JI, Jones W, et al. Bacterial vaginosis is associated with prematurity and vaginal fluid mucinase and sialidase: results of a controlled trial of topical clindamycin cream. Am f Obstet Gynecol 1994;170:1048-60.

2 Howe L, Wiggins R, Soothill PW, et al. Mucinase and sialidase activity of the vaginal flora: implications for the pathogenesis of preterm labour. Int F STD AIDS 1999;10:442-7.

3 Carlstedt I, Sheehan JK. Structure and macromolecular structure of cervical mucus glycoproteins. Symp Soc Exp Bio 1989;43:289-316.

4 Eggert-Kruse W, Botz I, Pohl S, et al. Antimicrobial activity of human cervical mucus. Hum Reprod 2000;15:778-84.

5 Zopf D, Roth S. Oligosaccharide anti-infective agents. Zapf D, Roth S. Oligosacci

Lancet 1996;347:1017-21.
6 Enhorning G, Huldt L, Melen B. Ability of cervical mucus to act as a barrier against bacteria. Am $\mathcal{F}$ Obstet Gynecol 970;15:532-7.

7 Elstein M. Functions and physical properties of mucus in the female genital tract. Br Med Bull 1978;34:83-8.

8 Scudder PR, Chantler EN. Control of human cervical mucin glycosylation by endogenous fucosyl and sialyltransferases. Adv Exp Med Biol 1982;144:265-7.

9 Corfield T. Bacterial sialidases - roles in pathogenicity and nutrition. Glycobiology 1992;2:509-521.

10 Odeblad E, Rudolfsson C. Types of cervical secretions: biophysical characteristics. In: Jordan JA, Singer S, eds. The
cervix. Philadelphia: WB Saunders, 1976;Ch 14:267-83.

11 Wickstrom C, Davies JR, Erikson GV, et al. MUC5B is major gel-forming, oligomeric mucin from human salivary major gel-forming, oligomeric mucin from human salivary gland, respirator glycofo

12 Gipson IK, Spurr-Michaud S, Moccia R, et al. MUC4 and MUC5B transcripts are the prevalent mucin messenger ribonucleic acids of the human endocervix. Biol Reprod 1999;60:58-64

13 Audie J-P, Tetaert D, Pigny P, et al. Mucin gene expression in the human endocervix. Hum Reprod 1995;10:98-102.

14 Gipson IK, Moccia R, Spurr-Michaud S, et al. The amount of MUC5B mucin in cervical mucus peaks at midcycle. f Clin End Metabol 2001;86:594-600.

15 Bagriacik E, Miller KS. Cell surface sialic acid and the regulation of immune cell interactions: the neuraminidase effect reconsidered. Glycobiology 1999;9:267-75.

16 Bardsley-Elliot A, Noble S. Oseltamivir. Drugs 1999;58: $851-60$

17 Kilian $M$, Reinholt $\mathrm{H}$, Poulsen $\mathrm{K}$, et al. Biological significance of IgA1 proteases in bacterial colonisation and pathogenesis: critical evaluation of experimental evidence. APMIS 1996;104:321-38.

18 Alugupalli KR, Kalfas S. Degradation of lactoferrin by periodontitis associated bacteria. FEMS Microbiol Lett 1996; 145:209-14. 
19 Stewart-Tull DE, Ollar RA, Scobie TS. Studies on the Vibrio cholerae mucinase complex. 1. Enzymic activities
associated with the complex. $₹$ Med Microbiol $1986 ; 2: 325-$ 33 .

20 Dwarakanath AD, Campbell BJ, Tsai HH, et al. Faecal mucinase activity assessed in inflammatory bowel disease using ${ }^{14} \mathrm{C}$ threonine labelled mucin substrate. Gut 1995;37 $58-62$

21 Connaris S, Greenwell P. Glycosidases in mucin-dwelling protazoans. Glycoconj $\mathcal{F}$ 1997; 14:879-82.

22 Macfarlane GT, Hay S, Gibson GR. Influence of mucin on glycosidase, proteinase and arylamidase activities of human gut bacteria grown in a 3-stage continuous culture system. f Appl Bacteriol 1989;66:407-17.

23 Lehker MW, Sweeney KD. Trichomonas invasion of the mucus layer require adhesins, mucinases and motility. Sex Transm Inf 1999;75:231-8.

24 De Repentigny L, Aumont F, Bernard K, et al. Characterisation of binding of Candida albicans to mucosal epithelial tion of binding of Candida albicans

25 Macfarlane C, Gibson GR. Formation of glycoprotein degrading enzymes by $\mathrm{B}$ fragilis. FEMS Microb Let degrading enzym

26 Roberton AM, Wright DP. Bacterial glycosulphatases and sulphomucin degradation. Can $\mathcal{F}$ Gastroenterol 1997;11: 361-6

27 Willis CL, Cummings JH, Neale G, et al. In vitro effects of mucin fermentation on the growth of human colonic sulphate-reducing bacteria. Anaerobe 1996;2:117-22.

28 Nieuw Amerongen AV, Bolscher JGM, Bloemena E, et al. Sulfomucins in the human body. Biol Chem 1998;379:1-18.

29 Drzeniek R. Viral and bacterial neuraminidases. Curr Top Microbiol Immunol 1972;59:35-74.

30 Corfield AP, Michalski J-C, Schauer R.The substrate specificity of sialidases from micro-organisms and mammals. Perspectives in Inherited Metabolic Diseases 1981;4:370 .

31 Vimr ER Microbial sialidases: does bigger always mean better? Trends Micro 1994;2:271-7.

32 Kelm S, Schauer R Sialic acid in molecular and cellular interactions. Int Rev Cytol 1997;175:137-240.

33 Reutter W, Stasche R, Stehling P, et al. The biology of sialic acids: insights into their structure, metabolism and function in particular during viral infection. In: Gabius H-J, Gabius S, eds. Glycosciences. London: Chapman and Hall, 1997; Ch 13:245-59.

34 Kirjavainen PV, Ouwehand AC, Isolauri E, et al. The ability of probiotic bacteria to bind to human intestinal mucus. FEMS Microbiol Lett 1998;167:185-9

35 Herold BC, Siston A, Bremer J, et al. Sulfated carbohydrate compounds prevent microbial adherence by STD pathogens. Antimic Ag Chem 1997;41:2776-80.

36 Briselden AM, Moncla BJ, Stevens CE, et al. Sialidases (neuraminidases) in bacterial vaginosis-associated microflora. 7 Clin Micro 1992;30:663-6.

37 Puapermpoonsiri S, Kato N, Watanabe $\mathrm{K}$, et al. Vaginal microflora associated with bacterial vaginosis in Japanese microflora associated with bacterial vaginosis in Japanese

38 Cauci S, Driussi S, Monte R, et al. Immunoglobulin A response against Gardnerella vaginalis hemolysin and sialidase activity in

39 Wiggins R, Crowley T, Horner PH, et al. Use of 5-bromo-4chloro-3-indolyl-alpha-D-N-acetylneuraminic acid in a novel spot test to identify sialidase activity from women with bacterial vaginosis. $\mathcal{F}$ Clin Micro 2000;38: 3096-7.

40 Costerton JW Overview of microbial biofilms. F Indust Microbiol 1995;15:137-40.

41 Godoy VG, Dallas MM, Russo TA, et al. A role for Bacteroides fragilis neuraminidase in bacterial growth in 2 model systems. Infect Immun 1993;61:4415-26.
42 Guzman CA, Plate M, Pruzzo C. Role of neuraminidasedependent adherence in $\mathrm{B}$ fragilis attachment to human dependent adherence in B fragilis attachment to
epithelial cells. FEMS Micro Lett 1990;59:187-92.

43 Namavar F, Van der Bijl MW, Appelmelk BJ, et al. The role of neuraminidase in haemagglutination and adherence to colon WiDr cells by B fragilis. F Med Micro 1994;40:393-6.

44 Domingues RM, Cavalcanti SM, Andrade AF, et al. Sialic acid as a receptor of Bacteroides fragilis lectin-like adhesin. Int F Med Microb Virol Parasitol Inf Dis 1992;277:340-4.

45 Berg JO, Lindqvist L, Andersson G, et al. Neuraminidase in Bacteroides fragilis. Appl Environ Microbiol 1983;46:75-80.

46 Tanaka H, Ito F, Iwasaki T. Purification and characterization of a sialidase from Bacteroides fragilis SBT3182. Biochem Biophys Res Comm 1992;189:542-9.

47 Gibson SA, Macfarlane GT. Characterization of proteases formed by B fragilis. F Gen Micro 1988;134:2231-40.

48 Moncla BJ, Braham P, Hillier SL. Sialidase (neuraminidase) activity among Gram-negative anaerobic and capnophilic bacteria. $\mathcal{F}$ Clin Micro 1990;28:422-5.

49 Gilks CB, Reid PE, Clement PB, et al. Histochemical changes in cervical mucus secreting epithelium during the normal menstrual cycle. Fertil Steril 1989;51:286-91.

50 Kahane I, Reisch-Saada A, Almagor M, et al. Glycosidase activity of mycoplasmas. Zentralbl Bakteriol 1990;273:300

51 Robertson JA, Stemler ME, Stemke GW. Immunoglobulin A protease activity of Ureaplasma urealyticum. I Clin Microbiol 1984;19:255-8.

52 Smith DG, Russel WC and Thirkell D. Adherence of Ureaplasma urealyticum to human epithelial cells. Microbiology 1994;140:2893-8

53 Vetere A, Borriello SP, Fontaine E, et al. Characterisation of anaerobic curved rods (Mobiluncus spp) isolated from the urogenital tract. F Med Microbiol 1987;23:279-88.

54 Murray PA, Kern DG, Winkler JR. Identification of a galactose-binding lectin on Fusobacterium nucleatum. Infect Immun 1988;56:1314-9.

55 Mangan DF, Novak MJ, Vora SA, et al. Lectinlike interactions of Fusobacterium nucleatum with human interactions of Fusobacterium nucleatum

56 Ruseler-van Embden JG, van Lieshout LM. Increased faecal glycosidases in patients with Crohn's disease. Digestion 987;37:43-50

57 Von Nicolai H, Hammann R, Salehnia S, et al. A newly discovered sialidase from $\mathrm{G}$ vaginalis. Zentrab Bakteriol Mikrobiol Hyg [A] 1984;258:20-6.

58 Coombs GH, North MJ. An analysis of the proteinases of Trichomonas vaginalis by polyacrylamide gel electrophoresis. Parasitology 1983;86:1-6.

59 Garber GE, Lemchuk-Favel LT. Analysis of the extracellular proteases of Trichomonas vaginalis. Parasitol Res 1994;80: $361-5$.

60 Bozner P, Demes P Proteinases in Trichomonas vaginalis and Tritichomonas mobilensis are not exclusively of the cysteine type. Parasitology 1991;102:113-5.

61 Padilla-Vaca F, Anaya-Velazquez F. Biochemical properties of a neuraminidase of Trichomonas vaginalis. $\mathcal{F}$ Parasitol 1997;83:1001-6.

62 Yolken RH. Enzymatic analysis for rapid detection of microbial infection in human bodily fluids: an overview. Clin Chem 1981;27:1490-8.

63 Wellmer A. Adhesion of clinical Candida albicans isolate to buccal epithelial cells. Mycoses 1999;42:43-7.

64 Hedges SR, Mayo MS, Mestecky J, et al. Evaluation of mmunoglobin A1 (IgA1) protease and IgA1 protease-in activity in human female genital infection with Neisseria gonorrhoea. Infect Immun 1998;66:5826-9.

65 Pritchard DG, Lin B. Group B streptococcal neuraminidase is actually a hyaluronidase. Infect Immun 1993;61:3234-9.

66 Swanson AF, Kuo CC. Identification of lectin-binding proteins in Chlamydia species. Infect Immun 1991;58:502-7. 